\title{
Psychiatric disorders in patients with systemic lupus erythematosus: association of anxiety disorder with shorter disease duration
}

\author{
Tomasz Hawro • Maria Krupińska-Kun • Jolanta Rabe-Jabłońska • \\ Anna Sysa-Jędrzejowska • Ewa Robak · Jarosław Bogaczewicz • Anna Woźniacka
}

Received: 4 July 2010/Accepted: 14 November 2010/Published online: 7 December 2010

(C) The Author(s) 2010. This article is published with open access at Springerlink.com

\begin{abstract}
Physicians' awareness about neuropsychiatric syndromes in systemic lupus erythematosus (SLE) is not rarely limited to seizures and psychoses included in the American College of Rheumatology (ACR) classification. Involvement of the central nervous system (CNS) with its rich symptomatology still belongs to the faintly recognised and understood aspects of lupus. The objective was to investigate prevalence and clinical correlations of psychiatric disorders in SLE patients. Fifty-two SLE patients were included. Disease duration and current and cumulative corticosteroid doses were calculated. Disease activity was assessed with the Systemic Lupus Activity Measure (SLAM). All subjects were examined by a psychiatrist. Psychiatric disorders were classified according to ACR criteria for neuropsychiatric systemic lupus erythematosus (NPSLE). Mini-Mental State Examination (MMSE) and Clock Drawing Test (CDT) were used to screen for cognitive impairments. Mental disorders were diagnosed in 16 (30.77\%), depressive disorder in $6(11.54 \%)$, cognitive dysfunction in $5(9.62 \%)$, anxiety disorder in $4(7.69 \%)$ and psychosis in one patient $(1.92 \%)$. SLE duration was shorter in patients diagnosed with anxiety disorder $(P<0.05)$, and cumulative dose of corticosteroids was lower in patients with anxiety disorder $(P<0.01)$. There was high positive correlation between SLE duration and cumulative dose of
\end{abstract}

T. Hawro $(\square)$ - A. Sysa-Jędrzejowska · E. Robak ·

J. Bogaczewicz · A. Woźniacka

Department of Dermatology and Venereology,

Medical University of Lodz, 5 Krzemieniecka Street,

94-017 Lodz, Poland

e-mail: t.hawro@yahoo.pl

M. Krupińska-Kun · J. Rabe-Jabłońska

Department of Affective and Psychotic Disorders,

Medical University of Lodz, Lodz, Poland corticosteroids $(r=0.684, P<0.001)$. Shorter SLE duration in patients with anxiety disorder seems to reflect its adaptative nature.

Keywords Systemic lupus erythematosus - Mental disorders · Anxiety disorders - Central nervous system lupus vasculitis - Depressive disorder - Psychotic disorders

\section{Introduction}

Systemic lupus erythematosus (SLE) is an autoimmune disorder that may involve many different tissues and organs, producing a broad spectrum of signs and symptoms. The most prevalent are arthritis with arthralgia and cutaneous lupus erythematosus [1]. Both high prevalence and visible manifestation explain an important role that has always been ascribed to skin lesions in SLE diagnosis. Adversely, the involvement of the central nervous system with its rich symptomatology belongs to the faintly recognised and understood aspects of lupus. Though neuropsychiatric symptoms often precede the other complaints, they rarely lead to diagnosis of SLE [2].

Classification and nomenclature of nervous system disorders in lupus evolved, from the first proposed in 1979 by Kassan and Lockshin [3], through Singer and Denburg criteria [4] to current classification of neuropsychiatric systemic lupus erythematosus (NPSLE), published in 1999 by the American College of Rheumatology (ACR) Research Committee [5]. Dissemination of the ACR classification for NPSLE serves more accurate diagnosis, better recognition and understanding of nervous system disorders in SLE. Alas till now many physicians of different specialties recognise only two NPSLE disorders, namely seizures and psychoses, included in the criteria for SLE [6]. 
ACR classification of NPSLE recognises five groups of psychiatric disorders: mood disorder, anxiety disorder, cognitive dysfunction, psychosis and acute confusional state [5].

The aim of the study was to investigate prevalence and clinical correlations of psychiatric disorders in SLE patients.

\section{Patients and methods}

The study comprised 52 SLE in- and outpatients (49 women, 3 men) of dermatology department, aged 20-69 years, mean age $42.46 \pm 12.75$ years. SLE diagnosis was made according to the ACR classification [6]. Disease duration was 6 months to 47 years, mean 8.91 years \pm 9.2 years. Approximate cumulative life dose of corticosteroids and current daily dose of corticosteroids (being administered no shorter than for last 14 days of therapy), for each patients were calculated. The dose was recalculated for prednisone if the patient received corticosteroids other than prednisone. Disease activity was measured with the Systemic Lupus Activity Measure (SLAM), according to the patients' last month history and results of clinical and laboratory examination performed during the last month [7]. The outcomes may range 0 (inactive)-86 (maximum disease activity). All the enrolled patients were examined by a specialist of psychiatry who diagnosed psychiatric disorders according to the International Statistical Classification of Diseases and Related Health Problems 10th Revision (ICD-10) and ACR criteria of NPSLE [5, 8]. Mini-Mental State Examination (MMSE) and Clock Drawing Test (CDT) were used as the screening tools for cognitive impairment [9, 10]. MMSE assesses memory, orientation, attention, verbal fluency, nominal aphasia, receptive aphasia with receptive apraxia, alexia, agraphia, constructional apraxia, whereas CDT assesses spatial dysfunction and neglect. CDT may detect executive cognitive dysfunction in patients with normal MMSE. Those of the patients who failed CDT or scored lower than 27 in MMSE were further examined neuropsychologically.

\section{Statistical analysis}

Descriptive statistics including mean, standard deviation, median, lower and upper quartile were calculated for the examined variables. The normality of distribution was tested with Shapiro-Wilk test. Non-parametric MannWhitney $U$ test was used for the comparison of variables between tested groups with and without psychiatric disorders, which were not normally distributed. Pearson's correlation analysis was used to investigate relation between SLE duration and cumulative corticosteroid dose. $\mathrm{P}$ values lower than 0.05 were considered statistically significant. The analysis was performed by means of Statistica v 8.0 software.

\section{Results}

Cumulative corticosteroid dose was in range 0-123 g, mean $27.12 \pm 30.6 \mathrm{~g}$ and current dose 0-60 mg, mean $11.80 \pm 14.12 \mathrm{mg}$. Disease activity in the examined group ranged 3-34, mean $12.20 \pm 5.97$.

Active mental disorders were diagnosed in 16 among the 52 examined SLE patients $(30.77 \%)$. Mood disorders were diagnosed in 6 patients $(11.54 \%)$. In all the cases, it was depressive disorder, whereas manic/submanic and mixed mood disorders were not observed. Cognitive dysfunction was diagnosed in 5 patients $(9.62 \%)$, anxiety disorder in 4 $(7.69 \%)$, psychosis in one patient $(1.92 \%)$. There was no significant difference in SLE activity between subgroups with and without diagnosed active mental disorders. Cumulative corticosteroid dose in the group of patients with diagnosed anxiety disorders (median $=2.1 \mathrm{~g}$, lower quartile $=1.0 \mathrm{~g}$, upper quartile $=2.2 \mathrm{~g}$ ) was lower than in patients without anxiety disorders (median $30.0 \mathrm{~g}$, lower quartile $=3.6 \mathrm{~g}$, upper quartile $=36.5 \mathrm{~g}$ ). The difference was statistically significant (Mann-Whitney $U$ test, $U=17 ; P<0.01$ - -Table 1. There was no relationship between the other mental disorders and cumulative dose of corticosteroids-Table 1. There was no relationship between current dose of corticosteroids and diagnosis of mental disorders. In the group of patients with anxiety disorder, SLE duration was shorter (median $=1.5$ years, lower quartile $=1.0$, upper quartile 3.0 years) than in the patients without anxiety disorder (median $=7.0$ years, lower quartile 3.0, upper quartile $=12.0$ years $)$ - Table 2 . The difference was statistically significant (Mann-Whitney $U$ test, $U=34 ; P<0.05)$-Fig. 1 .

There was no relationship between SLE duration and the other mental disorders. High positive correlation between SLE duration and cumulative dose of corticosteroids was observed (Pearson's $r=0.684, P<0.001$ ).

\section{Discussion}

Central nervous system involvement takes a special place among other organ disorders in the course of SLE, being responsible for a more severe course of the disease. It is one of the main causes of morbidity in patients with SLE [11]. The summarised prevalence of neurologic and psychiatric disorders in SLE was estimated by different authors at 80-91\% [1, 5, 12, 13]. Estimated prevalence of psychiatric syndromes alone is even more heterogeneous 
Table 1 Comparison of cumulative corticosteroid dose, expressed as gram of prednisone, in the subgroups of SLE patients with and without active mental disorders
$N S$ not significant

"+" present active disorder

"_" absent active disorder

\begin{tabular}{|c|c|c|c|c|c|}
\hline \multirow[t]{2}{*}{ Mental disorders } & & \multicolumn{3}{|c|}{ Cumulative dose of corticosteroids (g) } & \multirow{2}{*}{$\begin{array}{l}\text { Mann-Whitney } U \text { test } \\
U \text { ( } P \text {-value })\end{array}$} \\
\hline & & Median & Lower quartile & Upper quartile & \\
\hline \multirow[t]{2}{*}{ Mood disorders } & + & 42.0 & 27.0 & 42.0 & \multirow[t]{2}{*}{ NS } \\
\hline & - & 21.5 & 3.0 & 30.0 & \\
\hline \multirow[t]{2}{*}{ Anxiety disorders } & + & 2.1 & 1.0 & 2.2 & \multirow[t]{2}{*}{$17(0.009)$} \\
\hline & - & 30.0 & 3.6 & 36.5 & \\
\hline \multirow[t]{2}{*}{ Cognitive dysfunction } & + & 20.0 & 6.5 & 67.0 & \multirow[t]{2}{*}{ NS } \\
\hline & - & 24.5 & 2.7 & 36.0 & \\
\hline \multirow[t]{2}{*}{ Mental disorders (total) } & + & 18.5 & 2.2 & 42.0 & \multirow[t]{2}{*}{ NS } \\
\hline & - & 26.0 & 3.6 & 34.0 & \\
\hline
\end{tabular}

Table 2 Comparison of SLE duration in the subgroups of SLE patients with and without active mental disorders

\begin{tabular}{|c|c|c|c|c|c|}
\hline \multirow[t]{2}{*}{ Mental disorders } & & \multicolumn{3}{|c|}{ SLE duration (years) } & \multirow{2}{*}{$\begin{array}{l}\text { Mann-Whitney } U \text { test } \\
U(P \text {-value })\end{array}$} \\
\hline & & Median & Lower quartile & Upper quartile & \\
\hline \multirow[t]{2}{*}{ Mood disorders } & + & 11.0 & 11.0 & 17.0 & \multirow[t]{2}{*}{ NS } \\
\hline & - & 5.0 & 2.0 & 11.0 & \\
\hline \multirow[t]{2}{*}{ Anxiety disorders } & + & 1.5 & 1.0 & 3.0 & \multirow[t]{2}{*}{$34(0.039)$} \\
\hline & - & 7.0 & 3.0 & 12.0 & \\
\hline \multirow[t]{2}{*}{ Cognitive dysfunction } & + & 8.0 & 5.0 & 29.0 & \multirow[t]{2}{*}{ NS } \\
\hline & - & 5.5 & 2.0 & 11.0 & \\
\hline \multirow[t]{2}{*}{ Mental disorders (total) } & + & 11.0 & 2.0 & 15.0 & \multirow[t]{2}{*}{ NS } \\
\hline & - & 5.0 & 2.5 & 11.0 & \\
\hline
\end{tabular}

$N S$ not significant

"+" present active disorder

"_" absent active disorder

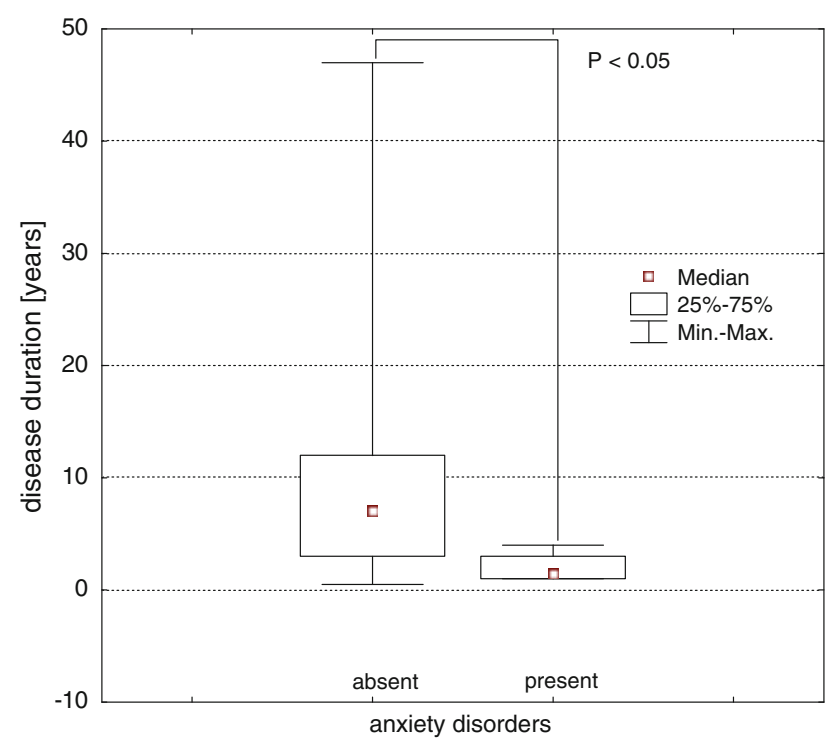

Fig. 1 Comparison of SLE duration in the SLE patients with and without anxiety disorders, $P<0.05$

between different centres. Authors claimed that mood disorders were present in 6-44\% of SLE patients, and these were mainly depressive disorders, whereas manic or mixed disorders were present in $0-4.4 \%[13,14]$. Cognitive dysfunction was observed by different authors in 55-80\% of SLE patients [12, 13], anxiety in 13-27\% and psychosis in $0-6.5 \%[13,15]$. The most frequent in the examined patients were depressive disorders, whereas the second place was taken by cognitive dysfunction followed by anxiety and psychosis. Total prevalence of psychiatric disorders in general population, according to the previous epidemiologic studies, was estimated for both genders to be approximately $17 \%$ [16]. The obtained data compared to a prevalence of mental disorders in adult general population show higher total psychiatric morbidity in SLE patients.

Cognitive and consciousness disorders included in the NPSLE criteria are matter of both neurology and psychiatry. Acute consciousness impairment (called, following ACR nomenclature acute confusional state) according to ACR is an acute qualitative and quantitative impairment of consciousness, which was not provoked by metabolic disorders, ingested drugs and psychoactive drug withdrawal. According to the ICD-10 and DSM-IV diagnostic criteria, term delirium refers to the same states. The authors of NPSLE classification notice that neurologists often use term encephalopathy to describe the same clinical state [5].

Brain blood perfusion disturbances resulting from occlusion of vessels supplying nervous tissue as well as immediate interactions of antibodies with neurons and glia are considered to be the most important mechanisms underlying NPSLE aetiology. Theoretically, the same processes may lead to both neurologic and psychiatric 
disorders. Lim et al. observed relationship between psychoses and neurological disturbances in the course of NPSLE [17]. However, the relationship was not seen in the other psychiatric symptoms. Tendency towards unified approach to psychiatric and neurologic disorders in the course of SLE and creation of "neuropsychiatric" syndromes category is also criticised [18]. Depressive-anxious psychopathologic syndromes are often hard to authoritatively differentiate if result from underlying organic pathogenesis or rather from a negative influence of hard, chronic and highly unpredictable disease on patient's psyche and thus being adaptative disorders [19, 20].

Many authors indicated relationship between NPSLE and SLE activity but mainly for neurologic symptoms [2, 19]. Most authors failed to find a relationship between psychiatric symptoms and SLE activity [21]. Shortall et al. did not observe any relationship between psychiatric disorders and SLE activity, whereas they observed a relationship between anxiety and mood disorders and psychosocial factors [22]. Ishikura et al. proved that prevalence and intensity of anxious and depressive symptoms in the course of SLE positively correlated with insufficient knowledge on disease and its therapy, perceived by the patient at the beginning of disease, and did not correlate with SLE activity [23]. The quoted observations are in accordance with presented results that failed to prove a relationship between SLE activity and psychiatric symptoms.

In the analysed group, shorter SLE duration in patients with anxiety disorder was observed. It may be speculated that anxiety resulted in these patients from inadequate knowledge on the course of disease and treatment methods. The knowledge acquired successively during the course of disease and development of effective coping strategies may be responsible for a lower rate of anxiety disorder in patients with longer SLE duration. McCracken et al. proved that patients presenting more efficient coping strategies and perceiving better social support featured decreased depressive symptoms and better social functioning [24]. The obtained results and literature data may suggest that at least part of anxious disorders encountered to NPSLE has adaptative background.

It seems that the observed lower cumulative dose of corticosteroids in patients with anxiety disorders may be explained by shorter disease duration in these groups. The thesis is confirmed by high positive correlation between cumulative dose and disease duration.

The shorter SLE duration in patients with anxiety disorder seems to argue for its adaptative nature and may, at least partially, result from insufficient information on disease and treatment perceived by patient on early stages of SLE, as well as from lack of efficient coping strategies developed. These observations should justify the need for psychological help addressed to patients with newly diagnosed SLE.

Acknowledgments This work was supported by the Medical University of Lodz [grant number 503-11521].

Conflict of interest The authors declare that they have no conflict of interest.

Open Access This article is distributed under the terms of the Creative Commons Attribution Noncommercial License which permits any noncommercial use, distribution, and reproduction in any medium, provided the original author(s) and source are credited.

\section{References}

1. Cervera R, Khamashta MA, Font J, Sebastiani GD, Gil A, Lavilla P, Mejía JC, Aydintug AO, Chwalinska-Sadowska H, de Ramón E, Fernández-Nebro A, Galeazzi M, Valen M, Mathieu A, Houssiau F, Caro N, Alba P, Ramos-Casals M, Ingelmo M, Hughes GR (2003) Morbidity and mortality in systemic lupus erythematosus during a 10 -year period: a comparison of early and late manifestations in a cohort of 1000 patients. Medicine (Baltimore) 82:299-308

2. Feinglass EJ, Arnett FC, Dorsch CA, Zizic TM, Stevens MB (1976) Neuropsychiatric manifestations of systemic lupus erythematosus: diagnosis, clinical spectrum, and relationship to other features of the disease. Medicine (Baltimore) 55:323-339

3. Kassan SS, Lockshin MD (1979) Central nervous system lupus erythematosus. The need for classification. Arthritis Rheum 22:1382-1385

4. Singer J, Denburg JA (1990) Diagnostic criteria for neuropsychiatric systemic lupus erythematosus: the results of a consensus meeting. J Rheumatol 17:1397-1402

5. ACR Ad Hoc Committee on Neuropsychiatric Lupus (1999) The American College of Rheumatology nomenclature and case definitions for neuropsychiatric lupus syndrome. Arthritis Rheum 42:599-608

6. Hochberg MC (1997) Updating the American College of Rheumatology revised criteria for the classification of systemic lupus erythematosus. Arthritis Rheum 40:1725

7. Liang MH, Socher A, Roberts WN, Esdaile JM (1988) Measurement of systemic lupus erythematosus activity in clinical research. Arthritis Rheum 31:817-825

8. World Health Organisation (1992) International statistical classification of diseases and related health problems, 10th revision. World Health Organisation, Geneva

9. Folstein M, Folstein S, McHugh P (1975) Mini-mental state: a practical method for grading the cognitive state of patients for the clinicians. J Psychiatr Res 12:189-198

10. Sunderland T, Hill J, Mellow A, Lawlor B, Gundersheime J, Newhouse P, Grafman J (1989) Clock drawing in Alzheimer's disease. A novel measure of dementia severity. J Am Geriatr Soc 37:725-729

11. Sibley JT, Olszynki WP, Decoteau E, Sundaram MB (1992) The incidence and prognosis of central nervous system disease in systemic lupus erythematous. J Rheumatol 19:47-52

12. Ainiala H, Hietaharju A, Loukkola J, Peltola J, Kornela M, Metsanoja R, Auvinen A (2001) Validity of the new American College of Rheumatology criteria for neuropsychiatric lupus syndromes: a population-based evaluation. Arthritis Rheum $45: 419-423$ 
13. Brey RL, Holliday SL, Saklad AR, Navarrete MG, HermosilloRomo D, Stallworth CL, Valdez CR, Escalante A, del Rincon I, Gronseth G, Rhine CB, Padilla P, McGlasson D (2002) Neuropsychiatric syndromes in lupus. Prevalence using standardized definitions. Neurology 58:1214-1220

14. Mok CC (2001) Neuropsychiatric manifestations and their clinical associations in southern Chinese patients with systemic lupus erythematosus. J Rheumatol 28:766-771

15. Ainiala H, Loukkola J, Peltola J, Korpela M, Hietaharju A (2001) The prevalence in neuropsychiatric syndromes in systemic lupus erythematosus. Neurology 57:496-499

16. Bijl RV, Ravelli A, van Zessen G (1998) Prevalence of psychiatric disorder in the general population: results of the Netherlands Mental Health Survey and Incidence Study (NEMESIS). Soc Psychiatry Psychiatr Epidemiol 33:587-595

17. Lim LC, Lee T, Boey M (1991) Psychiatric manifestation of systemic lupus erythematosus in Singapore. A cross-cultural comparison. Br J Psychiatry 159:520-523

18. Iverson GL (1995) The need for psychological services for persons with systemic lupus erythematosus. Rehabil Psychol 40:39-49
19. Abel T, Gladman DD, Urowitz MB (1980) Neuropsychiatric lupus. J Rheumatol 7:325-333

20. Segui J, Casals MR, Carrasco MG, de Flores T, Cervera R, Valdes M, Font J, Ingelmo M (2000) Psychiatric and psychosocial disorders in patients with systemic lupus erythematosus: a longitudinal study of active and inactive stages of the disease. Lupus 9:584-588

21. Wekking EM (1993) Psychiatric symptoms in systemic lupus erythematosus: an update. Psychosom Med 55:219-228

22. Shortall E, Isenberg D, Newman SP (1995) Factors associated with mood and mood disorders in SLE. Lupus 4:272-279

23. Ishikura R, Morimoto N, Tanaka K, Kinukawa N, Yoshizawa S, Horiuchi T, Nakashima H, Otsuka T (2001) Factors associated with anxiety, depression and suicide ideation in female outpatients with SLE in Japan. Clin Rheumatol 20:394-400

24. McCracken LM, Semenchuk EM, Goetsch VL (1995) Crosssectional and longitudinal analyses of coping responses and health status in persons with systemic lupus erythematosus. Behav Med 20:179-187 